\title{
Le corps, medium créatif et épistémologique, aux origines et dans la connaissance du « réel merveilleux » d'Alejo Carpentier $^{1}$
}

EDWIGE CALLIOS 2

1 Trabalho apresentado nas Journées scientifiques internationales (10-12 avril 2014) : «e corps en mouvement. Les mouvements du corps. Emotions et passions dans la création artistique et littéraire " Axe de recherche «Interactions et dynamiques créatrices en Europe et en Amérique(s) » du laboratoire CRINI (Centre de Recherche sur les Identités Nationales et l'Interculturalité), Nantes, Faculté des Langues et Cultures Etrangères.

2 Edwige Callios, Maître de Conférences, Université de Nantes, CRINI. Axe de recherche «Interactions et dynamiques créatrices en Europe et en Amérique(s) » du laboratoire CRINI (Centre de Recherche sur les Identités Nationales et l'Interculturalité), Nantes, Faculté des Langues et Cultures Etrangères. edwige.callios@gmail.com 


\section{- RESUME}

Le discours qui entoure les expériences artistiques les plus récentes nous incite aujourd'hui à reconsidérer le rôle du corps dans le processus créatif du « réel merveilleux » et à émettre l'hypothèse d'un corps medium, à la fois support et vecteur de médiation. Le corps en tant que potentiel de production et non plus seulement de représentation, a donné lieu au cours des dernières décennies à des expériences artistiques inédites. La peinture d'action, le body art, les performances scéniques, développées dès les années 1940, ont contribué à élargir le champ d'application de la notion de medium en conférant au corps un statut non plus seulement d'objet -objet de représentation, objet d'art- mais de sujet -sujet agissant. Dans des pratiques artistiques qui engagent le corps de l'artiste dans le processus créatif en tant que medium artistique, le corps devient à la fois sujet agissant et support de l'activité d'art sans jamais cesser d'être cependant objet de création. C'est à la croisée de ces trois dynamiques que semble se situer le processus créatif du "réel merveilleux », dans ses états premiers et dans ses variations. Pour comprendre le rôle du corps dans la connaissance du « réel merveilleux », sa prise de conscience et l'acte de création qu'elle suscite, il nous faut revenir sur les potentialités signifiantes de la notion de medium.

\section{- MOTS-CLES}

Alejo Carpentier, réel merveilleux, corps créatif.

\section{- RESUMO}

O discurso que cerca hoje as experiências artísticas, as mais recentes, nos incita a reconsiderar o papel do corpo no processo criativo do "real maravilhoso" e a emitir a hipótese de um corpo mediador, por vezes suporte e vetor de mediação. O corpo, enquanto potencial de produção e não apenas de representação deu lugar, nas últimas décadas, a experiências artísticas inéditas. A pintura da ação, o corpo arte, as performances cênicas, desenvolvidas desde os anos 1940, contribuíram para alargar o campo de aplicação da noção de mediador conferindo ao corpo um estatuto não mais de objeto - objeto de representação, objeto de arte mas de sujeito - sujeito agente. Nas práticas artísticas que engajam o corpo do artista no processo criativo enquanto mediador, o corpo torna-se sujeito agente e suporte da atividade da arte sem jamais cessar de ser objeto de criação. É no cruzamento destas três dinâmicas que parece se situar o processo criativo do "real maravilhoso" em seu estado primeiro e em suas variações. Para compreender o papel do corpo no conhecimento do "real maravilhoso", sua tomada de consciência e o ato de criação que ele suscita, é preciso retornar sobre as possibilidades significantes da noção de mediador.

\section{- PALAVRAS-CHAVE}

Alejo Carpentier, real maravilhoso, corpo criativo.

Le discours qui entoure les expériences artistiques les plus récentes nous incite aujourd'hui à reconsidérer le rôle du corps dans le processus créatif du « réel merveilleux » et à émettre l'hypothèse d'un corps medium, à la fois support et vecteur de médiation. Le corps en tant que potentiel de production et non plus seulement de représentation, a donné lieu au cours des dernières décennies à des expériences artistiques inédites. La peinture d'action, le body art, les performances scéniques, développées dès les années 1940, ont contribué à élargir le champ d'application de la notion de medium en conférant au corps un statut non plus seulement d'objet - objet de représentation, objet d'art- mais de sujet - sujet agissant. Dans des pratiques artistiques qui engagent le corps de l'artiste dans le processus créatif en tant que medium 
artistique, le corps devient à la fois sujet agissant et support de l'activité d'art sans jamais cesser d'être cependant objet de création. C'est à la croisée de ces trois dynamiques que semble se situer le processus créatif du « réel merveilleux », dans ses états premiers et dans ses variations. Pour comprendre le rôle du corps dans la connaissance du « réel merveilleux », sa prise de conscience et l'acte de création qu'elle suscite, il nous faut revenir sur les potentialités signifiantes de la notion de medium.

La notion de medium ne va pas de soi en littérature. Empruntée aux Beaux-arts, elle désigne le matériau, intellectuel ou palpable par lequel s'exprime le sens. Ces dernières décennies, elle a vu son champ d'application s'étendre et accueillir dans sa définition de nouveaux matériaux tels que le corps et des supports dématérialisés, les médiums dits « technologiques » par exemple (à l'origine du net art, bio art...). Etymologiquement, « medium » signifie « qui est au milieu, intermédiaire, au centre »3 et comme l'explique Jacques Rancière, dans un article intitulé « Ce que « medium » peut vouloir dire » :

Dans le mot « medium », on entend d'abord « ce qui se tient entre » : entre une idée et sa réalisation, entre une chose et sa reproduction. Le medium apparaît ainsi comme un intermédiaire, comme le moyen d'une fin ou l'agent d'une opération (RANCIERE, 2013). ${ }^{4}$

Le medium « donne accès à un milieu sensible inédit ». II permet « aux choses de se donner à voir ». Dans le processus de création du « réel merveilleux », le corps de l'artiste-écrivain semble remplir cette fonction.

Le « réel merveilleux » est d'abord la prise de conscience de l'omniprésence du merveilleux dans la réalité américaine, son histoire, ses légendes, son quotidien. De retour en Amériques, à l'occasion d'un voyage en Haïti, Alejo Carpentier réalise que le mélange du réel et du fantastique, le monde magique, que les surréalistes français et anglais s'évertuent à recréer à travers ce qu'il appelle «les vieux clichés de la forêt de Brocéliande, des chevaliers de la table ronde, de Merlin l'Enchanteur et du cycle d'Arthur ${ }^{5}$ », «par des tours de prestidigitation » ou encore en puisant dans «la boîte à outils à faire peur du roman noir anglais », est présent en continu en Amériques. II n'est pas à inventer mais à capter. II est un réel sur lequel l'artiste doit d'abord opérer une saisie avant de proposer une œuvre qui permettra au lecteur d'accéder à son tour à cet inconscient du visible qu'est le réel merveilleux.

Alejo Carpentier a explicité sa démarche artistico-politico-littéraire dans un essai édité en 1948 et transformé l'année suivante en prologue à son roman intitulé le Royaume de ce monde. L'analyse des processus dynamiques décrits dans le prologue, comparée à son application concrète dans le roman, révèle l'importance du corps et des fonctions sensorielles dans la prise de conscience du réel merveilleux et dans l'acte de création qu'elle suscite. Ce n'est pas par déduction qu'Alejo Carpentier accède au réel merveilleux, mais par immersion dans le sensorium haïtien :

A fines del año $\underline{1943}$ tuve la suerte de poder visitar el reino de Henrí Christophe [...]

\footnotetext{
3 Dictionnaire Latin/Français., Tournai, Hatier, 1993.

4 RANCIERE Jacques, "Ce que medium peut vouloir dire : l'exemple de la photographie ", Revue Appareil, $N^{\circ}$ 1,2008 mis à jour le 23/7/2013.

5 Extraits du "Prologue" au Royaume de ce monde.
} 
Después de sentir el nada mentido sortilegio de las tierras de Haití, de haber hallado advertencias mágicas en los caminos rojos de la Meseta Central, de haber oído los tambores del Petro y del Rada, me vi llevado a acercar la maravillosa realidad vivida a la acotante pretensión de suscitar lo maravilloso que caracterizó ciertas literaturas europeas de estos últimos treinta años. [...] Esto se me hizo particularmente evidente durante mi permanencia en Haití, al hallarme en contacto cotidiano con algo que podríamos llamar lo real maravilloso. Pisaba yo una tierra donde millares de hombres ansiosos de libertad creyeron en los poderes licantrópicos de Mackandal [...] Había respirado la atmósfera creada por Henri Christophe [...] A cada paso hallaba lo real maravilloso (CARPENTIER, 2007). ${ }^{6}$

Sa prise de conscience du réel merveilleux ne relève pas d'abord de la mentalisation -même si la mentalisation entre à divers degrés dans le processus de créationelle relève d'abord de la sensorialité. L'artiste écrivain fait l'expérience du réel merveilleux par imprégnation au contact de la réalité magique qui imprègne les lieux -les lieux d'histoire, les lieux de vie- et l'ordre social haïtien, anticipant en cela la théorie du corps de Merleau-Ponty dans L'œil et l'esprit, le corps «touchant/touché », « voyant/ vu », le corps « doublure externe » de l'âme, abolissant toute limite entre le corps et le monde entrelacés dans toute sensation. C'est par l'entremise du corps, qu'Alejo Carpentier accède à un milieu sensible inédit, celui d'Haïti, celui de la Caraïbe et plus largement encore celui de l'Amérique pénétrée d'influences culturelles (animisme, vaudou, christianisme) qui rendent une partie de sa réalité insaisissable par la raison seule car échappant à la grille de lecture formée par les structures a priori de l'esprit. Mais on remarque dans le passage cité plus haut que le vocabulaire est ceptuel, pour reprendre la terminologie de Léonard Talmy. Alejo Carpentier recourt à un vocabulaire primitivement perceptuel et gestuel en référence au toucher, au déplacement pour exprimer des processus intellectuels. Le « réel merveilleux », aux origines du processus créatif qui le fait émerger en tant que projet artistico-politico-littéraire, projet qui aura la résonnance qu'on lui connait dans les arts et dans les constructions identitaires américaines, opère un bouleversement dynamique dans la manière de concevoir le corps, siège des émotions mais également outil de connaissance car ce sera aussi par le corps, à travers les modalités sensorielles du discours littéraire, que l'artiste écrivain sera amené à faire accéder le lecteur à cet autre niveau de réalité. Aussi, l'approche ceptuelle du merveilleux semble-t-elle être la manifestation d'une réconciliation du corps et de la raison aux origines de ce processus créatif.

Dans le prologue au Royaume de ce monde, Alejo Carpentier soutient que les surréalistes français échouent à proposer un merveilleux littérairement authentique et impute cet échec au décalage qu'il perçoit entre l'offre littéraire et les croyances des lecteurs. La dynamique de comparaison avec l'art européen et de rejet de ses champs d'application ouvre la voie à une opération de saisie sur le réel, proprement américaine, et qui engage la foi. D'après l'auteur, le merveilleux est opérant lorsqu'il entre en concordance avec les croyances intimes, profondes, du lecteur, avec ses attentes et ses schémas de pensée naturels -ce qui n'est pas le cas selon lui du merveilleux qui sous-tend la légende arthurienne ou l'univers fantasmagorique des romans anglais, devenu anachronique dans l'histoire des croyances des lecteurs

6 CARPENTIER Alejo, "Prólogo", El reino de este mundo, Madrid, Alianza Editorial, 2007. 
français et anglais du XXème siècle. Pour saisir la réalité américaine dans toute sa complexité et faire accéder le lecteur à cet invisible du visible, l'artiste et le lecteur doivent partager -le temps de cette expérience artistique tout au moins- les croyances des peuples américains, aux miracles et à la magie. Or comment susciter cet acte de foi chez un lecteur profane, un lecteur ne partageant pas a priori les croyances animistes des esclaves haïtiens, ni leurs pratiques vaudous?

Dans le processus de création du réel merveilleux, l'artiste écrivain place au cœur de son dispositif non pas le logos mais la foi et privilégie la voie intuitive. De la même manière que la prise de conscience du réel merveilleux et l'acte de création qu'elle suscite engagent le corps et les fonctions sensorielles de l'artiste, la conceptualisation du réel merveilleux attendue du lecteur engage la cognition et privilégie dans le texte la voie associative. L'architecture cognitive du Royaume de ce monderoman exemplaire dans le projet du réel merveilleux- exploite des processus cognitifs issus de notre ordinaire mental, des processus dynamiques, le plus souvent associatifs. Les métaphores, les métonymies, les analogies, le contrepoint sont plus que des figures de styles ou des procédés littéraires venant soutenir et enrichir l'esthétique baroque du roman. Ils engagent le corps et l'esprit du lecteur dans le processus créatif. Dans ce dispositif artistico-littéraire le lecteur est amené à « voir » le réel merveilleux et à le conceptualiser par la médiation d'un personnage dont la caractérisation fait ressortir les fonctions sensorielles et les structures cognitives impliquées dans le rapport au monde magique. En Amériques, d'après Alejo Carpentier, le merveilleux est partout, mais comme le disait Michelet à propos du peuple, "il faut des yeux faits à cette douce lumière » (MICHELET, 1992, p. 63). ${ }^{7}$

La stratégie narrative mise en œuvre dans le récit conduit le narrataire à épouser le point de vue d'un personnage portant sur la réalité un regard magique. Le récit du narrateur à la troisième personne à focalisation sur le personnage de Ti Noel instaure une empathie entre le point de vue de ce personnage ainsi privilégié et le narrataire qui adopte sa vision du monde. De cette manière, «l'altération de la réalité », le « miracle » au fondement même du merveilleux dans l'esthétique d'Alejo Carpentier, est d'abord « perçue » en focalisation interne, comme appréhendée et accréditée simultanément par le personnage et par le lecteur, avant que son caractère insolite ne soit révélé par un changement de focalisation.

La technique du contrepoint et les opérations mentales qu'elle implique, d'association, de transformation, de projection, et de transferts conceptuels, engagent pleinement le lecteur dans le processus de création en ce sens qu'elles requièrent de lui non seulement qu'il s'implique dans la construction du sens mais également qu'il adhère le temps de l'expérience artistique au point de vue proposé. Cet engagement d'abord requis par les conditions d'émergence du merveilleux évoquées par l'artiste écrivain dans le prologue -« la sensation du merveilleux présuppose une foi »-, a pour effet d'immerger le lecteur dans l'espace mental haïtien, un espace métissé, certains diront syncrétique, où se côtoient et parfois se mélangent deux visions du monde, deux façons d'appréhender la réalité, le monde européen représenté par les colons français et le monde américain pénétré d'influences multiples en grande partie héritées en Haïti des transferts de population servile depuis le Golfe du Benin, le Dahomey et le Nigéria en particulier.

MICHELET, Le peuple, Paris, Flammarion, 1992, p. 63. 
Dans le récit, ces deux mondes coexistent et le narrataire y accède, par le jeu des focalisations, à l'origine d'une alternance entre deux perspectives, une perspective magique et intuitive d'une part et d'autre part une perspective rationaliste et déductive. Dans le processus créatif du réel merveilleux, en effet, le narrateur assume une fonction de régie. La réalité qu'il décrit est magique mais sa vision ne l'est pas. C'est d'ailleurs en partie ce qui différencie le processus créatif du réel merveilleux du processus créatif du « réalisme magique » comme l'a expliqué Leonardo Padura Fuentes par exemple. Le récit du narrateur donne à voir l'insolite et révèle ce faisant les prodiges de la foi, les métamorphoses de Makandal, les pouvoirs surnaturels de Maman Loi.

Néanmoins, en plaçant au cœur de son dispositif non pas le logos mais la foi et en privilégiant la voie associative, Alejo Carpentier conduit le lecteur à faire l'expérience d'une méthode d'accès à la connaissance plus intuitive, issue du patrimoine anthropologique haïtien. Les conditions -matérielles mais également émotionnelles et intellectuelles- qui fondent la prise de conscience du réel merveilleux et l'acte de création qu'elle génère, s'impriment dans l'œuvre à travers la dévalorisation de l'être au monde occidental. Le « réel merveilleux » en tant que projet artistique, politique et littéraire répond à un double mouvement de désillusion - désillusion causée par la situation politique de l'Europe dans les années 1940 renforcée par la lecture d'Oswald Spengler, Le Déclin de l'Occident et les productions surréalistes- et d'émerveillement devant la richesse du patrimoine américain.

Dès le premier chapitre, la technique du contrepoint et la focalisation du récit sur le personnage de Ti Noël placent le lecteur en situation de « voir » le monde occidental à travers les « yeux » d'un personnage haïtien. Outre sa plasticité, le titre «Têtes de cire » active un domaine notionnel allant bien au-delà de la «tête de cire », matérielle et utilitaire, employée dans le commerce des perruques. La tête de cire possède en effet un ensemble de propriétés physiques et culturelles acquises par opposition à la tête pensante : elle est artificielle, ne pense pas et ne ressent pas. Le regard de Ti Noël en se posant successivement sur les têtes de cire, les têtes des maîtres blancs, et les têtes de veaux, construit une référence par ricochet. En analysant le processus cognitif engagé par ces transferts et leur intégration, on constate que les propriétés matérielles et culturelles des têtes de cire (regard éteint, artificialité) et celles des têtes de veaux (lenteur et lourdeur, réjouissances de table, matérialisme) se mélangent à celles des têtes des messieurs blancs (rationalisme, primat de la raison, corps enveloppe) pour configurer l'image mentale d'une civilisation occidentale focalisée sur l'aspect mécanique et physique des choses, une civilisation « au regard éteint », « aux oreilles fermées », en somme une civilisation anthropocentriste et décadente.

En outre, la voie associative privilégiée dans ce mode opératoire est le vecteur d'une pensée logique en rupture avec la pensée occidentale, une pensée fondée sur l'analogie et la description, une pensée qui concilie le corps, « doublure externe de l'âme ", le corps sentant, entrelacé au monde- et l'esprit. Dès l'incipit, ce mode de pensée fait l'objet d'une valorisation à travers les qualités prêtées au personnage de Ti Noël. Il est celui qui voit ce que son maître ne voit pas, celui qui comprend la logique cachée du monde. L'anthropologue Philippe Descola a défini l'animisme comme « l'imputation par les humains à des non-humains d'une intériorité identique 
à la leur » (DESCOLA, 2005, p. 183). ${ }^{8}$ Par intériorité, il faut entendre une âme, une subjectivité, une intentionnalité. D'après l'ethnologue Alfred Metraux, en créole, le mot « namn », âme, a pris un sens « plus vague » et dans le vaudou haïtien, il signifie « force », « principe spirituel » ou encore « sacré » (MEATRAUX, 2003, p. 136)..$^{9}$ Ainsi, dans la perspective magique qu'Alejo Carpentier choisit pour faire accéder le lecteur au réel merveilleux, tout ce qui existe recèle une âme, et tout ce qui existe est sacré. La pensée animiste est une manière de voir le monde et de l'organiser fondée sur la croyance que toutes les entités qui le composent sont faites d'un substrat universel permanent, qu'une continuité matérielle unit tous les organismes. L'opérateur de différenciation n'est donc pas l'âme mais le corps, organique et vivant, qui permet à chaque espèce, selon les mots de Philippe Descola, « d'occuper un certain habitat et d'y mener un certain type d'existence par laquelle on l'identifie ».

Aussi la focalisation du récit sur le personnage de Ti Noël fait-elle émerger des schémas de pensée naturels que le temps de l'expérience artistique le lecteur est amené à épouser. Ces schémas de pensée, a la fois support et vecteur de médiation entre l'espace mental du lecteur et l'espace cible du réel merveilleux, engagent les sens. La vue, l'ouie, le toucher prennent une part active dans les processus dynamiques et associatifs qui sous-tendent cette vision du monde et dans l'immédiateté de ce rapport au monde. L'illettrisme et la place de la tradition orale dans la transmission des savoirs, affirmés dès l'ouverture du récit, sont le signe d'une autre façon de «lire » le monde, de le déchiffrer et de s'y inscrire. Le rapport âme/corps s'en trouve bouleversé.

Dans le processus créatif du réel merveilleux, le corps - ses sens, son mouvement interne, sa foi- est donc bien « ce qui se tient entre », entre le monde sensible américain, dans sa complexité magique et sa représentation littéraire, entre le geste politique -d'affranchissement des modèles européens et d'appropriation identitaireet sa réalisation artistique. Le corps est un intermédiaire. C'est par son entremise que l'auteur prend conscience du merveilleux et c'est à travers la mise en place d'un dispositif discursif destiné à reproduire les mouvements internes du corps organique et vivant, du corps pensant, que le lecteur accède à ce milieu sensible inédit qu'est le « réel merveilleux ». A la fois milieu dans lequel la performance artistique de l'artiste écrivain vient s'inscrire et milieu que cette performance contribue à configurer, le « corps pensant » devient le lieu d'une expérience inédite pour le lecteur, mais pas exclusive puisqu'à la faveur d'une technique narrative spécifique, la technique du contrepoint, le « corps enveloppe » reçoit la même fonction. L'expérience du « corps pensant » donne cependant accès à une seconde vérité, à un second milieu sensible inédit, en lien avec l'épistémologie. Son rôle dans le processus créatif, dans la prise de conscience du réel merveilleux et dans l'œuvre proposée, le donne à voir comme un instrument de compréhension du monde, un corps métaphore -un corps qui porte l'esprit au-delà- mais aussi un corps réceptacle des interactions du réel, un « microcosme qui réverbère le macrocosme » (JOUSSE, 2008, p. 58). ${ }^{10}$, dirait l'anthropologue Marcel Jousse. II écrit d'ailleurs ces mots qui entrent en résonnance

\footnotetext{
8 DESCOLA Philippe, Par-delà nature et culture, Paris, Gallimard, 2005, p. 183.

9 METRAUX Alfred, Le vaudou haïtien, Paris Gallimard, 2003, p. 136.

10 JOUSSE Marcel, L'anthropologie du geste, Gallimard, 2008, p. 58.
} 
avec la caractérisation de Ti Noël dans le Royaume de ce monde :

Tout homme qui sait garder à ses organes leur fraicheur naïve et native, est capable de jeter sur une toile, de modeler de l'argile, de rythmer par le son ou d'exprimer dans les mots de sa langue, des aspects d'un réel encore inconnu et même insoupçonnés [...]. Son œil voit le non-vu, son oreille entend le non-entendu, sa main manie le non-manié. Pourquoi ? Simplement parce qu'il est lui (JOUSSE, 2008, p. 77). ${ }^{11}$

Le « corps pensant » et le « corps enveloppe » coopèrent donc dans l'acte de création du « réel merveilleux », la perspective occidentale servant à faire ressortir le merveilleux d'un réel perçu selon la perspective américaine mais leur coexistence révèle, en outre que le rationalisme occidental, consistant à croire que tout le réel est rationnel, est une manière parmi d'autres d'appréhender le réel. Aussi, le regard croisé Europe/Amérique semble-t-il s'incarner dans ce projet artistico-politico-littéraire, à travers l'engagement du corps- sa foi, ses sens- dans le processus de création comme medium créatif mais également épistémologique, opposant de fait au primat de la raison occidentale, au corps " enveloppe », une alternative issue de l'héritage sacré des peuples américains.

\section{Bibliographie selective}

CARPENTIER Alejo. El reino de este mundo. Madrid: Alianza Editorial, 2007.

CARPENTIER Alejo. "Prólogo", El reino de este mundo. Madrid: Alianza Editorial, 2007.

DAMOME, Etienne. "L'animisme en Afrique". Bordeaux, Cours donné en deuxième année de Master Religions et Sociétés, 2014.

DESCOLA Philippe. Par-delà nature et culture. Paris: Gallimard, 2005.

DESCOLA Philippe, «L'animisme est-il une religion ? », Les Grands dossiers des Sciences Humaines, n. 4, décembre 2006-janvier-février. 2007.

ESPERATTI-PINERO Emma Susana. Pasos hallados en El reino de este mundo. México: El colegio de México, 1981.

GONZALEZ ECHEVERRIA Roberto. Alejo Carpentier: El peregrino en su patria. Madrid: Gredos, 2004.

JOUSSE Marcel. L’anthropologie du geste. Gallimard, 2008.

LAPAIRE, Jean-Rémi. "Analyse linguistique du discours religieux. Religion et cognition. Glossaire et Diaporama », Bordeaux, Cours donné en deuxième année de Master Religions et Sociétés, 2013.

MARMOUZ Fatima. « Le corps est un medium extraordinaire » propos recueilli par Abdelghni Fennane, le 16 juillet. 2013. Disponible sur http://www.lemag.org

11 Ibid., p. 77. 
METRAUX Alfred. Le vaudou haïtien. Paris Gallimard, 2003.

PADURA FUENTES Leonardo. Un camino de medio siglo: Alejo Carpentier y la narrativa de lo real maravilloso. Ciudad de México: Fondo de cultura Económica, 2002.

PAZ SOLDAN Edmundo. "Alejo Carpentier: teoría y práctica de lo real maravilloso". Anales de Literatura Hispanoamericana, v. 37. 2008.

PEREZ CANTERO Ramón. "Huellas surrealistas en EI reino de este mundo de Alejo Carpentier", Universidad de Murcia.

RANCIERE Jacques. "Ce que medium peut vouloir dire : l'exemple de la photographie ", Revue Appareil, n. 1, 2008 mis à jour le 23/7/2013. Disponible sur http://revues.mshparisnord.org.

ROMERO R. Héctor. "Historia y realismo mágico en la visión haitiana de Alejo Carpentier en El reino de este mundo", Hipertexto 17, 163, 2013.

THIBAULT Kathleen. «Sophie Calle : le corps exposé ». Epistémocritique, 2008.

Disponible sur http://www.epistémocritique.org

VIGARELLO G., COURTINE et CORBIN. L'histoire du corps. Paris : Seuil, 2011. 3 v. 